\title{
Regional patterns of cardiac sympathetic denervation in patients with type 2 diabetes mellitus and it's relationship to autonomic dysfunction
}

\author{
Sabahat Bokhari ${ }^{1 *}$, Kathleen Hickey ${ }^{1}$ and Steven Bergmann ${ }^{2}$ \\ *Correspondence: sb605@columbia.edu \\ ${ }^{1}$ Columbia University Medical Center, Department of Medicine/Cardiology, 622 West $168^{\text {th }}$ Street, NY 10032, New York. \\ ${ }^{2}$ Beth Israel Medical Center, Department of Medicine/CardiologyFirst Ave at $16^{\text {th }}$ Street, NY 10003, New York.
}

\begin{abstract}
Objective: In this study we evaluated regional myocardial blood flow (MBF) and left ventricular (LV) sympathetic innervation using positron emission tomography (PET) and its relationship to standard autonomic function tests (AFT).

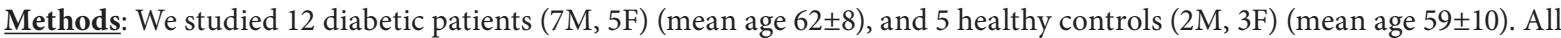
patients underwent AFT and cardiac PET imaging with oxygen-15 labeled water to measure myocardial blood flow (MBF) and carbon -11 hydroxyephedrine (HED) to assess presynaptic cardiac sympathetic nerves. HED images were read semiquantitatively (summed score 4 segment/4 point model) and quantitatively (3-compartment model) to quantify cardiac HED density and flux (B-max). Single compartment model was used for MBF quantification.

Results: All 5 controls had normal MBF, homogeneous uptake of HED, no regional difference in B-max and normal AFT. All 12 diabetic patients had normal MBF, 5 had homogeneous uptake of HED and 7 had heterogeneous uptake. The average HED defects summed score in diabetic patients was 9 in apical, 15 in basal lateral, 11 in distal lateral and 0 in septal region. In heterogeneous group there was a significant difference in B-max between the septal and lateral wall regions $(24 \pm 12$ vs.18 \pm 10$)$. On AFT all 12 diabetic patients had normal resting heart rate, RR and normal postural heart rate variability but $6 / 12$ had postural hypotension. All 6 of these patients had heterogeneous HED uptake.

Conclusions: Diabetic patients exhibited LV sympathetic dysfunction predominantly in the lateral wall region and only postural hypotension was significantly correlated with it.
\end{abstract}

Keywords: Myocardial blood flow, cardiac sympathetic innervation, positron emission tomography, diabetes mellitus, carbon-11 hydroxyephederine

\section{Introduction}

The incidence and prevalence of diabetes mellitus (DM) are increasing. Type $2 \mathrm{DM}$ is the most common form and accounts for $97 \%$ of cases worldwide. In 2005 , approximately 20.8 million US adults (7\%) had DM (14.6 million diagnosed and 6.2 million undiagnosed) as determined by elevated fasting glucose levels $(>126 \mathrm{mg} / \mathrm{dl})$. Approximately 54 million people in United States have impaired fasting glucose levels (100-125 mg/dl). About $20 \%$ to $40 \%$ of diabetics also have abnormal autonomic function on clinical testing, even when DM is first diagnosed [1-3].

Cardiac autonomic neuropathy is associated with increased morbidity and mortality and has been linked to the occurrence of sudden death. Diabetic patients with autonomic dysfunction, particularly sympathetic involvement as evidenced by postural hypotension, have a poor clinical prognosis with a high 5 -year mortality rate, approaching $50 \%$ in one series. [4-6]. The determination of the presence of cardiac autonomic neuropathy (CAN) is based on a battery of autonomic function tests. A consensus conference in 1992 recommended that three tests (heart rate variability, Valsalva maneuver, and postural blood pressure testing) be used for longitudinal testing of the cardiovascular autonomic system [1]. These autonomic function tests have been validated as clinical tools for diagnosing diabetic autonomic dysfunction. Proposed mechanisms of neuronal damage include metabolic abnormalities, neuronal ischemia, and immune mediated injury $[\mathbf{5 , 8}, \mathbf{9}]$.

Scintigraphic assessment of cardiac sympathetic integrity is possible with the use of radiolabeled analogues of norepinephrine, which are actively taken up by the presympathetic nerve terminals of the heart. Single photon imaging using radiolabeled ${ }^{123}$-metaiodobenzylguanidine (MIBG) and positron emission tomography (PET) using carbon-11 hydroxyephedrine (HED) for evaluating cardiac sympathetic nerve function have been reported $[10,20]$. HED has been shown to have a regionally homogeneous distribution in all the myocardial segments of the left ventricle in healthy individuals [10]. The objective of this study was to quantify global and regional cardiac HED uptake in patients newly diagnosed with Type $2 \mathrm{DM}$, and to determine whether there is a correlation between cardiac HED uptake, myocardial perfusion and autonomic dysfunction as assessed with physiologic testing. HED uptake was assessed quantitatively using a 
Bokhari et al. Journal of Diabetes Research and Clinical Metabolism 2013, http://www.hoajonline.com/journals/pdf/2050-0866-2-14.pdf

Table 1. Clinical Characteristics.

\begin{tabular}{llll}
\hline & Heterogeneous & Homogeneous & P value \\
\hline $\begin{array}{l}\text { Age (mean) } \\
\text { Gender (male/female) }\end{array}$ & $69 \pm 8$ & $75 \pm 5$ & NS \\
$\begin{array}{l}\text { Hypertension } \\
\text { (\%) }\end{array}$ & 100 & $3 / 2$ & NS \\
$\begin{array}{l}\text { Hyperlipidemia (\%) } \\
\text { Smoking History (\%) }\end{array}$ & 86 & 100 & NS \\
$\begin{array}{l}\text { Family History of } \\
\text { CAD (\%) }\end{array}$ & 29 & 80 & NS \\
$\begin{array}{l}\text { Fasting Blood } \\
\text { Glucose (mg/dl) }\end{array}$ & $150 \pm 49$ & 60 & NS \\
$\begin{array}{l}\text { Resting Heart Rate } \\
\text { (beats/min) }\end{array}$ & $68 \pm 8$ & 40 & NS \\
$\begin{array}{l}\text { Hemoglobin } \\
\text { A1C (\%) }\end{array}$ & $7.7 \pm 0.6$ & $815 \pm 1.6$ & NS \\
\hline All values are presented & NS \\
\hline
\end{tabular}

All values are presented as mean \pm SD.

3-compartment model that yielded a value for presynaptic receptor density $\left(\mathrm{B}_{\max }\right)$.

\section{Methods}

We studied a total of 17 subjects: 12 patients with uncontrolled type 2 DM (based on 1997 ADA criteria), 5 males and 7 females, with a mean age of $62 \pm 8$ years and 5 non-diabetic controls, 2 male and 3 female subjects, with a mean age of $59 \pm 10$. (Table 1). Investigators were blinded to the DM and control groups.

Patients were excluded if they had pre-existing CAD, congestive heart failure, previous cerebrovascular event, non-diabetic autonomic neuropathy secondary to Parkinson's disease, Shy-Drager syndrome, ethanol use, renal disease (serum creatinine $>1.5 \mathrm{mg} / \mathrm{dl}$ ), hepatic disease; body mass index $>45 \mathrm{k} / \mathrm{m}^{2}$, breast feeding or pregnant patients. Women of child bearing potential were required to have a negative urine pregnancy test on the morning of the study prior to PET scans. Patients taking medications known to interfere with neuronal uptake of norepinephrine analogue (tricyclic antidepressants, monoamine oxidase inhibitors, beta-blockers) abstained from such substances for at least 2 weeks before all studies.

\section{Autonomic function testing}

All study subjects were tested for cardiovascular autonomic neuropathy utilizing a set of standardized autonomic function tests. For six hours before the autonomic function tests, the subject was asked to avoid food, alcohol, caffeine containing drinks, smoking and insulin. For parasympathetic, testing heart rate variability was measured with deep breathing lying supine at a rate of 6 breaths/min and recorded for 2 minutes on a continuous EKG tracing. Maximal and minimal RR intervals during each respiratory cycle were recorded and the mean value for respiratory cycles was calculated in beats/min. For sympathetic testing, the postural change in systolic blood pressure was measured. The subject's blood pressure was recorded after lying supine for 10 minutes in a quiet room and measured again after standing for 1 minute. For combined parasympathetic and sympathetic testing, resting heart rate was calculated in beats/min as a mean value obtained over 5 minutes after 20 minutes of supine rest. The Valsalva maneuver was performed against a pressure of $40 \mathrm{mmHg}$ for 15 seconds and the ratio of the longest RR interval after the maneuver to the shortest RR interval during the maneuver was calculated. Investigators were blinded to autonomic function test results.

\section{PET imaging}

On a separate day after autonomic testing, patients underwent PET scans after an overnight fast. PET images were acquired on Siemens ECAT Accel high-resolution PET scanner (CTI Siemens, Knoxville, Tenn). All images were corrected for scatter and measured photon attenuation. Oxygen-15 labeled water $(0.3-0.4 \mathrm{mCi} / \mathrm{Kg})$ was administered by an intravenous bolus and a 5-minute dynamic scan was obtained for the assessment of myocardial perfusion. After decay of radioactivity to background levels, carbon-11 HED (10-20 mCi) was injected intravenously over 30 seconds. A dynamic 60-minute scan for HED uptake was then performed.

Image reconstruction was performed using iterative reconstruction and a Hann filter. Multiple transverse slices of the heart were obtained and standardized regions of interest are placed on the septum, apex and lateral myocardium. In addition, a region of interest in the basal left ventricular blood pool was monitored for input function. Myocardial perfusion in $\mathrm{ml} / \mathrm{g} / \mathrm{min}$ was assessed using a single compartment model by a standard mathematical approach developed and validated in our laboratory [11]. $B_{\max }$ was obtained in the same regions of interest using a 3-compartment model (Figure 1). We applied this formula to calculate $\mathrm{B}_{\text {max }} / \mathrm{K}_{\mathrm{d}}=\left(\mathrm{K}_{1} \times \mathrm{k}_{3}\right) /\left(\mathrm{k}_{2} \times \mathrm{k}_{4}\right)[12]$.

In addition to quantitative analyses, PET images were also assessed visually. For each study subject, the transaxial images obtained from PET scan were visually inspected and a score assigned to the HED uptake in each of the four regions of interest, the basal lateral wall, distal lateral wall, septum and apex. Scores were given based on the following scale: $0=$ Normal tracer uptake, $1=$ Mild reduction, $2=$ Moderate reduction, $3=$ Severe reduction or absent tracer activity. Summed score was based on 4 segment/ 4 point model. For each myocardial segment, the scores of all the diabetic patients were summated. Higher scores were consistent with more severe reduction of tracer uptake. Participants with a score of $\geq 2$ were defined as heterogeneous and participants with a score of less than 2 were defined as homogeneous.

Autonomic function tests and PET imaging were conducted by separate investigators and technicians. The cardiologists reading the PET scans were blinded to the results of the autonomic function tests and vice versa. 


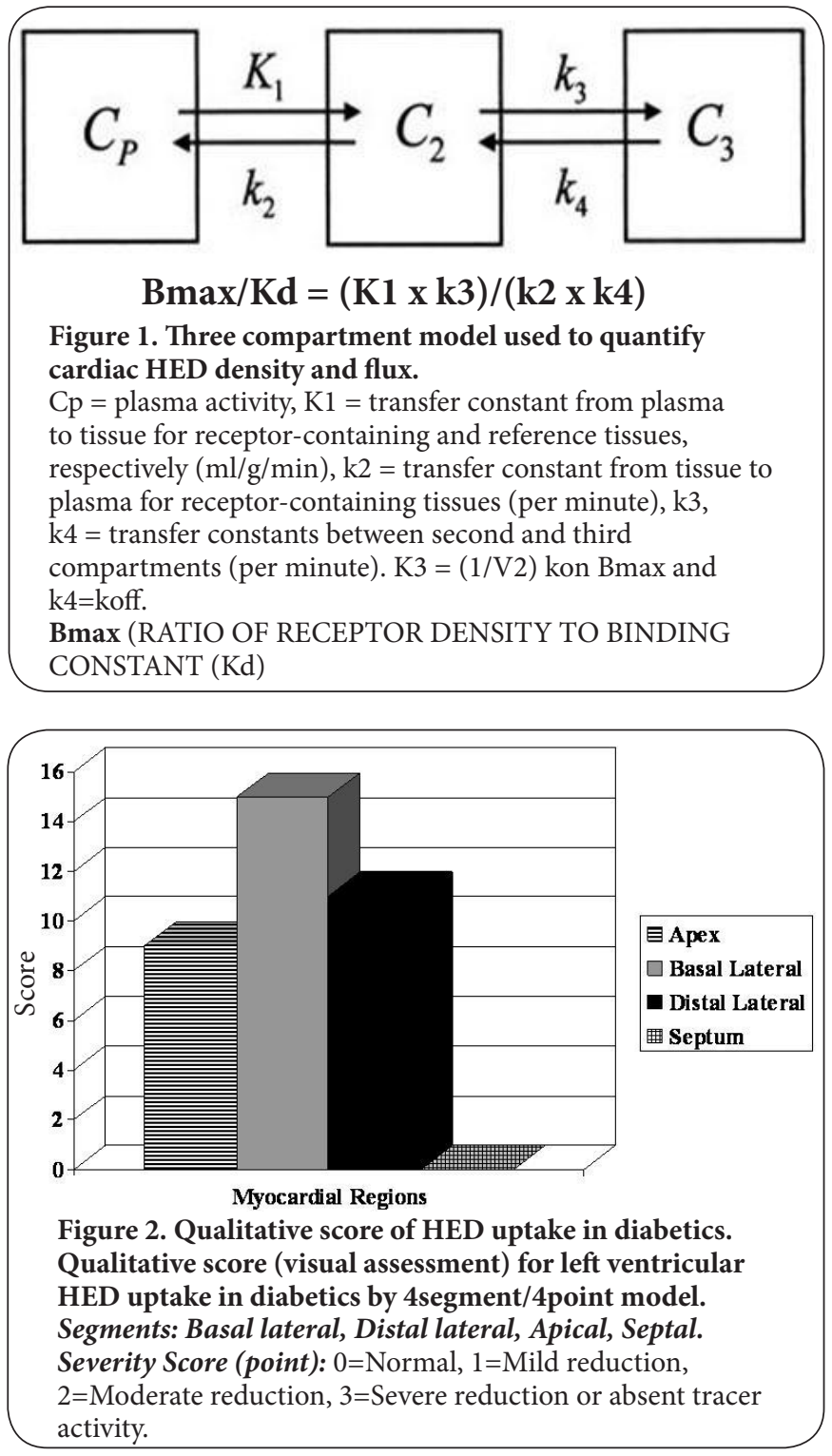

The study protocol was approved by the Institutional Review Board of Columbia University Medical Center as well as by the Radioactive Drug Research Committee and the Joint Radiation Safety Committee of the University.

\section{Statistical analysis}

Data are presented as mean \pm SD. HED data was correlated with each autonomic function test using the Spearman's coefficient for non-parametric variables. Tests for significant associations were conducted using a two-tailed student's t-test. Statistical significance was defined as a p value less than 0.05 .

\section{Results \\ Regional myocardial C-11 HED uptake}

In all the study participants, C-11 HED uptake was measured separately for the four segments of the left ventricle (basal lateral wall, distal lateral wall, apex, and septum). The tracer

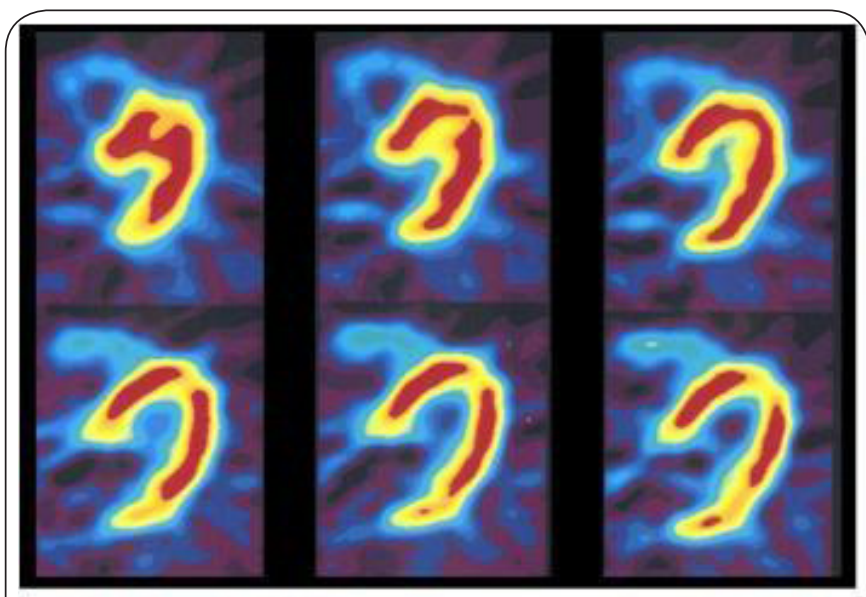

Figure 3. Mid-left ventricular trans-axial images of C-11 HED uptake in a diabetic patient without autonomic dysfunction.

In this figure, the septum is to the upper left, apex to the upper right, lateral wall to the lower right, and the discontinuity to the lower left represents the mitral valve plane.

uptake was evaluated by both visual and quantitative analyses. The diabetic patients were subdivided into 2 groups - Patients with heterogeneous HED uptake, and patients with homogeneous HED uptake.

\section{Visual assessment of tracer distribution}

Scores from all four LV segments showed homogeneous HED uptake in 5 diabetic patients, moderate to severe reduction of lateral wall tracer uptake in 6 patients with or without additional apical defects and isolated severely reduced uptake only in the apical region of one patient. The average score for the 6 patients with defects in the basal lateral LV wall was $2.5 \pm 0.8$ and the distal lateral region having a score of $1.8 \pm 1.1$. Basal lateral tracer uptake was reduced in all 6 patients and 5 out of 6 also had reduced tracer uptake in distal lateral region. Apical uptake was reduced in 3 patients and their average score was $1.5 \pm 1.6$. Tracer uptake was normal in the septum of all the diabetic patients; therefore, the summated score was 0 . The differences in the regional myocardial scores in the diabetic patients are illustrated in Figure 2. All five non-diabetic control subjects had normal tracer uptake in all four LV regions. Figure 3 shows the PET images of a diabetic patient with normal HED uptake in all the myocardial regions. Figure 4 shows PET images of a diabetic patient with severely reduced HED uptake in the basal lateral segment and moderately decreased HED uptake in the distal lateral segment.

\section{Quantitative analysis of C-11 HED uptake}

In the heterogeneous HED group, the mean $B_{\text {max }}$ in the lateral wall was significantly lower than that in the septum $(18 \pm 10$ vs. $24 \pm 12 \mathrm{P}=0.05$ ) despite equal blood flow. The mean $B_{\max }$ in the apical region was not significantly different from the $\mathrm{B}_{\max }$ measured in either the lateral wall or the septum. In 


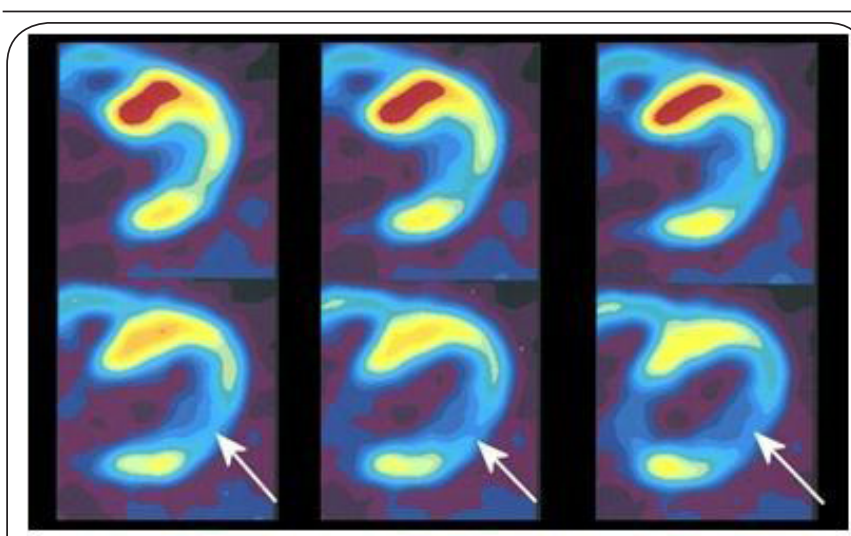

Figure 4. Mid-ventricular trans-axial images from a patient with DM and autonomic dysfunction.

There is severely decreased HED uptake in the basal lateral segment and moderately decreased HED uptake in the distal lateral segment.

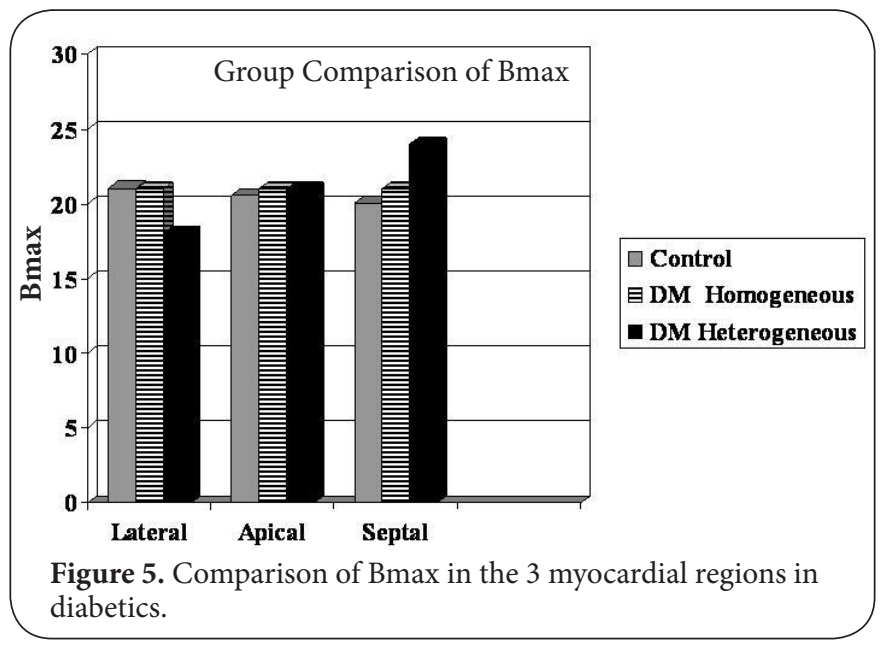

the 5 patients with homogeneous HED uptake, there was no significant difference in B-max between the septal, apical or lateral wall.

In non-diabetic subjects, the mean $B_{\max }$ in septal, apical or lateral either wall was not significantly different from each other. Figure 5 depicts the regional variations in $\mathrm{B}_{\max }$ seen in diabetic patients, but not observed in the control group. When compared to the control subjects, the diabetic subjects were found to have lower mean $B_{\max }$ in the lateral wall and higher $B_{\max }$ in the septum, with a trend towards statistical significance. Visual assessments of the septal, apical and lateral walls were correlated with the mean $B_{\max }$ in these walls. There was a good correlation between the visual assessment and the quantitative analysis.

\section{Regional myocardial perfusion}

The blood flow measurements in the apex, lateral wall and the septum were not significantly different from each other in heterogeneous, homogeneous, or the control groups
Table 2. Myocardial blood flow.

\begin{tabular}{lccll}
\hline & Lateral wall & Septum & Apex & Global \\
\hline $\begin{array}{l}\text { Diabetics with } \\
\text { heterogeneous }\end{array}$ & $1.19 \pm 0.36$ & $1.26 \pm 0.41$ & $1.27 \pm 0.41$ & $1.24 \pm 0.38$ \\
$\begin{array}{l}\text { HED uptake } \\
\begin{array}{l}\text { Diabetics with } \\
\text { homogeneous }\end{array}\end{array}$ & $1.22 \pm 0.33$ & $1.02 \pm 0.35$ & $1.40 \pm 0.33$ & $1.20 \pm 0.33$ \\
$\begin{array}{l}\text { HED uptake } \\
\text { Controls }\end{array}$ & $1.04 \pm 0.25$ & $1.01 \pm 0.22$ & $1.06 \pm 0.17$ & $1.04 \pm 0.19$ \\
\hline
\end{tabular}

All values are presented as mean blood flow in $\mathrm{ml} / \mathrm{g} / \mathrm{min} \pm \mathrm{SD}$.

Table 3. Autonomic function test results.

\begin{tabular}{|c|c|c|c|}
\hline & $\begin{array}{l}\text { Diabetics with } \\
\text { heterogeno HED } \\
\text { uptake }\end{array}$ & $\begin{array}{l}\text { Diabetics with } \\
\text { homogenous } \\
\text { HED uptake }\end{array}$ & Controls \\
\hline $\begin{array}{l}\text { Heart Rate at rest } \\
\text { (beats } / \mathrm{min}) \geq 90^{*}\end{array}$ & $70 \pm 11$ & $63 \pm 10$ & $59 \pm 9.5$ \\
\hline $\begin{array}{l}\text { Heart Rate Variability } \\
\text { (beats/min) } \leq 8^{\star}\end{array}$ & $8.0 \pm 2.0$ & $11 \pm 1.2$ & $12.0 \pm 1.6$ \\
\hline $\begin{array}{l}\text { Systolic BP on Standing } \\
(\mathrm{mm} \mathrm{Hg}) \geq 20^{*}\end{array}$ & $20 \pm 6^{*} \dagger$ & $9 \pm 4 \dagger$ & $8 \pm 4^{*}$ \\
\hline $\begin{array}{l}\text { All values are prese } \\
\cdot \text { Denotes criterion } \\
\cdot{ }^{*} \mathrm{P}<0.005 \\
\cdot \dagger \mathrm{P}<0.005\end{array}$ & $\begin{array}{l}\text { nted as mean } \pm S \\
\text { for abnormal tes }\end{array}$ & sults & \\
\hline
\end{tabular}

(Table 2). Comparing the heterogeneous HED uptake group with the homogeneous HED uptake group, no significant difference in myocardial blood flow was detected in any of the four LV segments. In patients with heterogeneous HED uptake, there was no significant difference in the blood flow among the four LV segments.

\section{Clinical tests of autonomic dysfunction}

There was no statistically significant difference noted in resting heart rate between the heterogeneous, group, homogeneous group and the controls There was also no statistically significant difference in heart rate variability among the three groups (Table 3 ). There was a statistically significant decrease in systolic blood pressure on standing (> $20 \mathrm{~mm} \mathrm{Hg}$ ) between heterogeneous group compared to the homogeneous group and between heterogeneous group compared to the controls but not between the homogeneous and control groups (Table 3).

\section{Discussion}

About half (58\%) of the diabetic patients in this study demonstrated regional variation in myocardial C-11 HED uptake with the majority of them showing reduced uptake in the lateral LV wall. These findings suggest destruction or dysfunction of sympathetic nerves preferentially in the lateral LV wall. Reduction of ${ }^{11} \mathrm{C}$-HED uptake was more severe in the basal portion of the lateral LV wall than the distal LV wall and apex. Heterogeneity in MIBG uptake has been reported in diabetics in previous study. These studies have reported 
a pattern of predominantly apical denervation and basal hyperinnervation [13]. Our findings show predominantly LV lateral wall sympathetic nerve destruction or dysfunction. There are major differences in our study and previous studies. All previous studies in diabetic patients have been with SPECT imaging using I-123 MIBG. This difference can be attributed to different isotopes, better resolution with PET imaging and the ability to do absolute quantification with PET imaging. To the best of our knowledge no other group has studied cardiac sympathetic nerve destruction or dysfunction in diabetic patients using ${ }^{11} \mathrm{C}$-HED PET imaging.

Cardiovascular autonomic neuropathy has been implicated as an independent risk factor for increased cardiovascular mortality in patients with diabetes [14-16]. Although it is difficult to determine the independent effects of CAN on mortality because of the co-existence of coronary artery disease, predisposition to malignant arrhythmias is considered to be one of the mechanisms by which autonomic neuropathy may cause increased mortality independent of myocardial ischemia [17]. Literature suggests that regions of sympathetic hyperinnervation by acting as foci of electrical instability, may contribute to ventricular arrhythmias and sudden cardiac death [13]. Therefore, the abnormalities of sympathetic nerve structure/function found in our diabetic participants may have prognostic implications.

Abnormalities of cardiac sympathetic nerve structure/ function observed in our PET studies correlated with abnormal tests of cardiovascular sympathetic function. Diabetic patients in this study with abnormalities of cardiac sympathetic nerve structure/function in PET images were noted to have postural hypotension consistent with decreased cardiovascular sympathetic reflexes. None of the diabetic patients with homogeneous HED uptake had postural hypotension.

Regional myocardial blood flow at rest was measured in all study subjects, to exclude decreased perfusion causing reduced tracer delivery and uptake. No significant difference was noted in the regional myocardial blood flow in diabetics, indicating that the decreased $\mathrm{B}_{\max }$ in the lateral wall was a result of decreased HED uptake by sympathetic nerves rather than diminished regional blood flow. Compared with healthy controls, the global blood flow was found to be higher in diabetics, although the difference was not statistically significant. Similar findings on myocardial perfusion have been reported in previous studies on diabetic patients $[18,19]$.

Abnormalities in sympathetic innervation have been seen on cardiac imaging in diabetic patients with normal cardiovascular reflex tests, suggesting direct cardiac imaging may be more sensitive in detecting CAN than indirect tests of autonomic function $[\mathbf{2 0}, \mathbf{2 1}]$. Most of the previously published studies have been conducted on patients with Type 1 diabetes. Our study is one of the few studies to evaluate the distribution of abnormalities of cardiac sympathetic nerve structure/ function in patients with Type 2 diabetes. Limitations of our study include the small sample size, as well as the non-age matched control subjects. The younger controls do not however affect our results on the regional differences in sympathetic innervation observed in the diabetic subjects.

Nevertheless, our findings are interesting and suggest that abnormalities of cardiac sympathetic nerve structure and/or function are common in T2 DM and often are present before the usual autonomic screening tests become abnormal. It is interesting that, of the standard screening tests for cardiac autonomic neuropathy, only postural hypotension is associated with the regional changes in structure/function of cardiac sympathetic nerves detected by PET images using ${ }^{11} \mathrm{C}-\mathrm{HED}$ as the imaging reagent. These striking findings should encourage additional studies of cardiac sympathetic nerves in a variety of pathologic states. By design, the present studies were kept simple by including patients with T2 DM of short duration and by excluding patients with known coronary heart disease.

\section{Conclusion}

We conclude that PET imaging with radiolabeled norepinephrine analogues e.g., HED can be used to delineate abnormalities of cardiac sympathetic nerve structure/ function in type $2 \mathrm{DM}$. We observed a pattern of sympathetic denervation in the lateral wall and hyperinnervation in the septum, which correlated with postural hypotension. Of the three standard autonomic function tests only postural hypotension was significantly correlated with cardiac sympathetic dysinnervation. Early detection of autonomic dysfunction on PET imaging would indicate need for more aggressive glucose control. Further studies are required to assess the prognostic value of this noninvasive modality in the diabetic population.

\section{Competing interests}

The authors declare that they have no competing interests.

\section{Publication history}

Received: 04-Jan-2013 Revised: 25-Feb-2013

Accepted: 08-Mar-2013 Published: 14-Mar-2013

\section{References}

1. Kahn R: Proceedings of a consensus development conference on standardized measures in diabetic neuropathy. Autonomic nervous system testing. Diabetes Care 1992, 15:1095-103. | Article | PubMed

2. Spallone $V$ and Menzinger $G$ : Diagnosis of cardiovascular autonomic neuropathy in diabetes. Diabetes 1997, 46 Suppl 2:S67-76. | Article | PubMed

3. Spallone V, Uccioli $L$ and Menzinger G: Diabetic autonomic neuropathy Diabetes Metab Rev 1995, 11:227-57. | Article | PubMed

4. Ewing DJ, Campbell IW and Clarke BF: Mortality in diabetic autonomic neuropathy. Lancet 1976, 1:601-3. I Article I PubMed

5. Samuels MA: Neurally induced cardiac damage. Definition of the problem. Neurol Clin 1993, 11:273-92. | Article | PubMed

6. Watkins PJ and Mackay JD: Cardiac denervation in diabetic neuropathy. Ann Intern Med 1980, 92:304-7. I Article I PubMed

7. Ziegler D, Gries FA, Muhlen H, Rathmann W, Spuler M and Lessmann F: Prevalence and clinical correlates of cardiovascular autonomic and peripheral diabetic neuropathy in patients attending diabetes centers. 
The Diacan Multicenter Study Group. Diabete Metab 1993, 19:143-51. | Article I PubMed

8. Greene DA, Lattimer SA and Sima AA: Pathogenesis and prevention of diabetic neuropathy. Diabetes Metab Rev 1988, 4:201-21. | Article | PubMed

9. McDougall AJ and McLeod JG: Autonomic neuropathy, I. Clinical features, investigation, pathophysiology, and treatment. J Neurol Sci 1996, 137:79-88. | Article | PubMed

10. Schwaiger M, Kalff V, Rosenspire K, Haka MS, Molina E, Hutchins GD, Deeb M, Wolfe E, Jr. and Wieland DM: Noninvasive evaluation of sympathetic nervous system in human heart by positron emission tomography. Circulation 1990, 82:457-64. | Article | PubMed

11. Bergmann SR, Herrero P, Markham J, Weinheimer CJ and Walsh MN: Noninvasive quantitation of myocardial blood flow in human subjects with oxygen-15-labeled water and positron emission tomography. J Am Coll Cardiol 1989, 14:639-52. | Article | PubMed

12. Ichise M, Meyer JH and Yonekura Y: An introduction to PET and SPECT neuroreceptor quantification models. J Nucl Med 2001, 42:755-63. | Article | PubMed

13. Stevens MJ, Raffel DM, Allman KC, Dayanikli F, Ficaro E, Sandford T, Wieland DM, Pfeifer MA and Schwaiger M: Cardiac sympathetic dysinnervation in diabetes: implications for enhanced cardiovascular risk. Circulation 1998, 98:961-8. | Article | PubMed

14. Ewing DJ, Campbell IW and Clarke BF: The natural history of diabetic autonomic neuropathy. Q J Med 1980, 49:95-108. | Article | PubMed

15. O'Brien IA, McFadden JP and Corrall RJ: The influence of autonomic neuropathy on mortality in insulin-dependent diabetes. Q J Med 1991, 79:495-502. | Article | PubMed

16. Rathmann W, Ziegler D, Jahnke M, Haastert B and Gries FA: Mortality in diabetic patients with cardiovascular autonomic neuropathy. Diabet Med 1993, 10:820-4. | Article | PubMed

17. Algra A, Tijssen JG, Roelandt JR, Pool J and Lubsen J: Heart rate variability from 24-hour electrocardiography and the 2-year risk for sudden death. Circulation 1993, 88:180-5. | Article | PubMed

18. Di Carli MF, Bianco-Batlles D, Landa ME, Kazmers A, Groehn H, Muzik O and Grunberger G: Effects of autonomic neuropathy on coronary blood flow in patients with diabetes mellitus. Circulation 1999, 100:813-9. | Article | PubMed

19. Stevens MJ, Dayanikli F, Raffel DM, Allman KC, Sandford T, Feldman EL, Wieland DM, Corbett J and Schwaiger M: Scintigraphic assessment of regionalized defects in myocardial sympathetic innervation and blood flow regulation in diabetic patients with autonomic neuropathy. J Am Coll Cardiol 1998, 31:1575-84. | Article | PubMed

20. Langen KJ, Ziegler D, Weise F, Piolot R, Boy C, Hubinger A, Gries FA and Muller-Gartner HW: Evaluation of QT interval length, QT dispersion and myocardial $\mathrm{m}$-iodobenzylguanidine uptake in insulin-dependent diabetic patients with and without autonomic neuropathy. Clin Sci (Lond) 1997, 93:325-33. | Article | PubMed

21. Ziegler D, Weise F, Langen KJ, Piolot R, Boy C, Hubinger A, Muller-Gartner HW and Gries FA: Effect of glycaemic control on myocardial sympathetic innervation assessed by [1231]metaiodobenzylguanidine scintigraphy: a 4-year prospective study in IDDM patients. Diabetologia 1998, 41:44351. | Article | PubMed

\section{Citation:}

Bokhari S, Hickey K and Bergmann S: Regional patterns of cardiac sympathetic denervation in patients with type 2 diabetes mellitus and it's relationship to autonomic dysfunction. Journal of Diabetes Research and Clinical Metabolism 2013, 2:14.

http://dx.doi.org/10.7243/2050-0866-2-14 